\title{
ANÁLISE HISTOPATOLÓGICA DO EPITÉLIO RENAL EM CAMUNDONGOS EXPOSTOS À INALAÇÃO DO HERBICIDA ÁCIDO 2,4 DICLOROFENOXIACÉTICO
}

\author{
Maria Fernanda Minzoni Malatrasi ${ }^{1}$, Maria Gabriela Tamanini ${ }^{1}$, Fabíola de Azevedo Mello ${ }^{1}$, Gabriela Vidotto \\ Cavalieri ${ }^{1}$, Débora Tavares de Resende e Silva ${ }^{2}$, Ana Karina Marques Salge ${ }^{3}$, Thiago Milani da Costa ${ }^{1}$, Abel \\ Gomes de Pinheiro Neto ${ }^{1}$, Bruna Maria Casachi Bernardes de Melo Carapeba ${ }^{1}$, Renata Calciolari Rossi ${ }^{1}$ \\ ${ }^{1}$ Universidade do Oeste Paulista - UNOESTE, Presidente Prudente, SP. ${ }^{2}$ Universidade Federal Fronteira do Sul - UFFS, \\ Chapecó, SC. ${ }^{3}$ Universidade Federal de Goiás - UFG, Goiânia, GO. e-mail: mfmalatrasi@gmail.com
}

\section{RESUMO}

Um dos herbicidas mais usados no Brasil, Ácido 2,4-diclorofenoxiacético (2,4-D), possui grau III de periculosidade. Sua excreção é principalmente renal, o que pode acarretar danos a esse sistema. $O$ objetivo do presente estudo foi avaliar as possíveis alterações histopatológicas em rins de camundongos da linhagem Swiss causadas pela exposição ao Ácido 2,4-diclorofenoxiacético. Para o experimento foram utilizados 80 camundongos Swiss adultos machos divididos em grupos, sendo esses, então, expostos ao herbicida. Após a eutanásia e autópsia, foram retirados os rins, e analisados histologicamente. O resultado obtido da análise estatística da área tubular e área da luz renal, juntamente com trabalhos já publicados, demonstraram que existe pouca evidência cientifica que mostre potencial inflamatório e/ou mutagênico da exposição aguda ao ácido 2,4-diclorofenoxiacético, porém, alterações podem existir levando-se em conta uma exposição crônica ao herbicida, logo, é necessário o desenvolvimento de mais pesquisas para futuros esclarecimentos e tomadas de decisões.

Palavras-chave: rim, herbicidas, Ácido 2,4-Diclorofenoxiacético, exposição ambiental.

\section{HISTOPATHOLOGICAL ANALYSIS OF RENAL EPITHELIUM IN MICE EXPOSED TO INHALATION OF THE HERBICIDE 2,4 DICHLOROPHENOXYACETIC ACID}

\begin{abstract}
One of the most widely used herbicides in Brazil, 2,4-dichlorophenoxyacetic acid (2,4-D), has a hazardous grade III. Its excretion is mainly renal, which can cause damage to this system. The objective of the present study was to evaluate the possible histopathological changes in Swiss mouse kidneys caused by exposure to 2,4-dichlorophenoxyacetic acid. For the experiment were used 80 male adult Swiss mice divided into groups, which were then exposed to the herbicide. After euthanasia and autopsy, the kidneys were removed and histologically analyzed. The results obtained from the statistical analysis of the tubular area and renal lumen area, together with previously published studies, have shown that there is little scientific evidence showing inflammatory and/or mutagenic potential of acute exposure to 2,4dichlorophenoxyacetic acid, however, changes can may exist due to chronic exposure to the herbicide, so further research is needed for further clarification and decision making.
\end{abstract}

Keywords: kidney, herbicides, 2,4-Dichlorophenoxyacetic acid, organophosphates, environmental exposure. 


\section{INTRODUÇÃO}

Defensivos agrícolas são produtos químicos, físicos ou biológicos usados no controle de seres vivos considerados nocivos ao homem, sua criação e suas plantações. São também conhecidos por agrotóxicos, pesticidas, praguicidas ou produtos fitossanitários. Dentre estes termos, o termo agrotóxico é o termo utilizado pela legislação brasileira ${ }^{1}$.

Uma das formas de utilização de agrotóxicos ainda em vigor no Brasil, apesar dos enormes impactos para o meio ambiente e para a saúde humana, consiste na aplicação aérea ${ }^{2}$.

A Empresa Brasileira de Pesquisa Agropecuária (Embrapa) apresenta estudos que comprovam a alta periculosidade da pulverização aérea. Ocorre a chamada "deriva técnica", de maneira que os atuais equipamentos de pulverização - mesmo com calibração, temperatura e ventos ideais - deixam $32 \%$ dos agrotóxicos pulverizados retidos nas plantas; outros $49 \%$ vão para o solo e $19 \%$ vão, pelo ar, para outras áreas circunvizinhas da aplicação.

Além dos danos provenientes da pulverização aérea de agrotóxicos, deve-se mencionar que as pragas agrícolas possuem capacidade de desenvolver resistência aos agrotóxicos aplicados, que, dessa forma, perdem gradativamente sua eficácia, levando os agricultores a aumentar as doses aplicadas e/ou recorrer a novos produtos ${ }^{2}$.

A Associação Brasileira de Saúde Coletiva (Abrasco), ao tratar do tema, assinala ser imperativo que o poder público proíba tal atividade, diante das doses cada vez maiores de contaminantes nos produtos tóxicos que têm sido aplicados principalmente em áreas de monocultura ${ }^{3}$.

No entanto, a legislação federal que regula os agrotóxicos no Brasil não proíbe tal atividade. Diferentemente, em muitos países a proibição da pulverização aérea já é uma realidade, a exemplo da Eslovênia ${ }^{3,4}$.

As consequências advindas da utilização de agrotóxicos no Brasil são condicionadas por: contexto e modo de produção químico dependente, relações de trabalho, toxicidade dos produtos utilizados como agrotóxicos e micronutrientes contaminados, precariedade dos mecanismos de vigilância da saúde, uso inadequado ou falta de equipamentos de proteção coletiva e individual. A situação de contaminação é agravada pelas precárias condições socioeconômicas e culturais da grande maioria dos trabalhadores rurais, o que amplia sua vulnerabilidade frente à toxicidade dos agrotóxicos ${ }^{5}$.

Os estudos de monitoramento de resíduos de agrotóxicos têm aumentado ano a ano e sinalizado que resíduos de agroquímicos estão presentes nos alimentos, na atmosfera ${ }^{6}$, nas precipitações secas e úmidas, como chuvas ${ }^{7}$, e nas águas superficiais e subterrâneas ${ }^{8}$.

Ao mesmo tempo em que o Estado brasileiro tem sido forte para liberalizar o uso de agrotóxicos, é frágil para monitorar e controlar seus danos à saúde e ao ambiente ${ }^{2}$.

No contexto de medidas de proteção à saúde da população, destaca-se a Política Nacional de Saúde Integral das Populações do Campo e da Floresta, de relevância indiscutível, ao tratar da saúde da população vulnerável aos impactos advindos do agronegócio no Brasil, bem como outros processos, e do compromisso do SUS em desenvolver políticas de atenção à saúde desses grupos ${ }^{5}$.

O Brasil está entre os maiores consumidores mundiais de agrotóxicos, correspondendo a $86 \%$ do consumo da América Latina ${ }^{9}$. Entre 1995 e 2006 as lavouras brasileiras cresceram $43,2 \%$, e junto disso cresceu o consumo de agrotóxico por hectare utilizado ${ }^{9}$.

Um dos principais ingredientes ativos comercializados no Brasil com o objetivo de combater pragas em lavouras é o ácido 2,4diclorofenoxiacético (2,4-D), ocupando a 6a posição nos mais utilizados. Essa substância é rotulada como herbicida, já que o mesmo visa controlar ervas daninhas ${ }^{9}$, e é utilizada em culturas de cana-de-açúcar, soja, milho, arroz ${ }^{10}$, trigo, aveia, sorgo, café e pastagens de Braquiária $^{11}$. Os produtos a base desde princípio ativo são classificadas como classe III de potencial de periculosidade ambiental, o que significa que são produtos perigosos ao meio ambiente ${ }^{12}$, pois são altamente transportáveis, persistentes e tóxicos para organismos aquáticos, mas são pouco tóxicos para organismos do solo e para aves e abelhas ${ }^{10}$.

De acordo com o Sistema de Informação de Agravos de Notificação (SINAN) foram registradas 2402 notificações de intoxicação por agrotóxico agrícola no Brasil em $2015^{13}$. Já pelo Sistema Nacional de Informações Tóxico-Farmacológicas (SINITOX) houve 3337 casos notificados no mesmo ano, demonstrando descrepância entre os dados colhetados pelos sistemas ${ }^{14}$. Posteriormente em 2017 o número de 
casos foi de 1085, de acordo com o SINITOX, porém o número de casos não decresceu, houve uma dimuição da participação dos Centros de Informação e assistência Toxicológica (CIATs) nos levantamentos. Portanto a comparação não é fidedigna. Não há dados mais atualizados disponíveis ${ }^{15}$.

Existem três vias com a quais podem ocorrer exposição aos agrotóxicos: a via ocupacional, onde pode ser desde a produção da substância, na pulverização e/ou durante a colheita. A segunda via possível é a ambiental, onde o contato se dá nos diversos componentes do meio ambiente, como lençóis freáticos e atmosfera. Por fim, existe aexposição pela via alimentar, onde a população em geral ingere resíduos de agrotóxicos presentes nos mais diversos alimentos, principalmente em sua superfície ${ }^{9,16}$.

No organismo humano o 2,4-D possui 84-94\% de excreção através da urina, principalmente se esta estiver alcalina, e excreção secundária (2-11\%) pelas fezes ${ }^{11}$.

Os rins desempenham duas funções primordiais no organismo: 1 . eliminação de produtos terminais do metabolismo orgânico, como uréia, creatinina e ácido úrico e, 2. controle das concentrações da água e da maioria dos constituintes dos líquidos do organismo, tais como sódio, potássio, cloro, bicarbonato e fosfatos. Quando a excreção não é totalmente eficaz ocorre a intoxicação ${ }^{17}$.

Os efeitos da intoxicação sobre a saúde humana podem ser classificados de duas maneiras:

- Agudos (resultantes da exposição ao agente tóxico com alto grau de toxicidade, onde os sintomas surgem de forma acelerada, algumas horas após a exposição excessiva por um curto período): mais visíveis, com características marcantes e que aparecem logo após a exposição ao agente ou durante o contato com ele ${ }^{18}$.

- Crônicos (exposição contínua a doses baixas): seus efeitos podem ser vistos após semanas, meses ou até anos após a exposição, sendo mais difíceis de serem identificados. Muitas vezes, acabam sendo confundidos com outras alterações e não relacionadas ao agente causador $^{19,20}$.

O objetivo do presente estudo foi analisar as alterações histopatológicas em rins de camundongos Swiss expostos à nebulização ao herbicida 2,4-D.

\section{METODOLOGIA}

Aspectos de natureza ética

Este estudo se encontra aprovado pelo Comitê de Ética em Animais da Universidade do Oeste Paulista (UNOESTE) sob o protocolo $4091 \mathrm{e}$ foi realizado de acordo com o Guia para o Cuidado e Uso de Animais de Laboratório do Instituto Nacional de Saúde (USA).

Caracterização da amostra e protocolo de exposição ao herbicida 2,4-D

Para a realização dos experimentos, foram utilizados 80 camundongos Swiss adultos machos (30-45g), fornecidos pelo Biotério Central da UNOESTE, alocados em gaiolas plásticas coletivas ( 5 animais por gaiola) medindo $600 \mathrm{X}$ 415 milímetros, a temperatura média de $22 \pm 2$ graus Celsius, com ciclos de $12 \mathrm{~h}$ de luminosidade, sendo das 07:00 as 19:00 horas (período claro) e 19:00 as 07:00 horas (período escuro)

O protocolo de experimentação contou com duas caixas ( $32 \times 24 \times 32 \mathrm{~cm})$, cada uma ligada a um nebulizador ultrassônico da marca Pulmosonic Star ${ }^{\circledast}$, onde foi administrada as seguintes concentrações diluídas em $5 \mathrm{~mL}$ de cloreto de sódio $0,9 \%$ :

- $\quad$ GS: Apenas $5 \mathrm{ml}$ de cloreto de sódio 0,9\%

- $\quad$ GBC: Solução composta por $15 \mu \mathrm{L}$ de 2,4 $\mathrm{D}$ diluídos em $5 \mathrm{ml}$ de cloreto de sódio $0,9 \%$;

- $\quad$ GMC: Solução composta por $25 \mu \mathrm{L}$ de 2,4D diluídos em $5 \mathrm{ml}$ de cloreto de sódio $0,9 \%$

- $\quad$ GAC: Solução composta por $37 \mu \mathrm{L}$ de 2,4D diluídos em $5 \mathrm{ml}$ de cloreto de sódio $0,9 \%$.

O tempo de exposição foi de aproximadamente $10 \mathrm{~min}$, tempo este necessário para que toda a solução seja nebulizada.

$\mathrm{Na}$ primeira exposição, todos os 80 camundongos foram submetidos à nebulização com a concentração preconizada para cada grupo. Após 24 h, 20 animais, sendo cinco de cada grupo, foram eutanasiados para a coleta do material. Após $48 \mathrm{~h}$, outros 20 animais que já receberam a segunda nebulização, também foram eutanasiados, então após 72 h, outros 20 animais que receberam a terceira nebulização, e finalmente, após 7 dias da primeira exposição, portanto totalizando 8 dias, os últimos 20 animais, que também já haviam recebido as três nebulizações, foram eutanasiados.

Coleta do material

Os modelos experimentais foram eutanasiados utilizando-se de tiopental sódico 
(30 $\mathrm{mg} / \mathrm{kg}$ do peso corporal) por via intraperitoneal. Após esta etapa foi realizada autopsia para retirada rins e posterior análise. 0 tecido renal foi coletado para o processamento e confecção dos blocos em parafina.

Protocolo de desidratação e inclusão do material A desidratação foi feita através de imersão numa bateria de soluções alcoólicas em concentrações graduais. A graduação nas concentrações é imprescindível para que ocorra a desidratação homogênea dos tecidos, evitando que ocorram danos na estrutura tecidual. Para a inclusão do material, o mesmo foi imerso em parafina líquida a $60^{\circ} \mathrm{C}$, obtendo-se, em temperatura ambiente, um bloco que contém o fragmento de tecido em seu interior. A partir desta etapa, foram levados para a microtomia, os cortes coletados em lâminas de vidro, e encaminhados para a coloração.

Análise histológica

Cortes de $5 \underline{\mu m}$ das amostras foram corados com Hematoxilina e Eosina para subsequente seleção das áreas renais mais apropriadas para avaliação morfológica e do infiltrado inflamatório.

O protocolo da técnica de Hematoxilina e Eosina consiste inicialmente em desparafinizar, alcoolizar (álcool absoluto) e hidratar. Após este procedimento mergulha-se em Hematoxilina de Harris por 5 min e lava-se em água corrente, em seguida mergulha-se a lâmina no diferenciador por $4 \mathrm{~s}$ (álcool ácido clorídrico) e lava-se rapidamente em água corrente. Após esta fase, o fragmento é então mergulhado em Eosina por 5 min, seguido por álcool absoluto, para posterior montagem em meio sintético com entelan.

Análise dos resultados morfológicos

Após realizada a coloração de Hematoxilina-Eosina, foi realizada a análise morfométrica dos túbulos renais dos animais estudados, utilizando-se o software Image pro plus $^{\circledR}$. Para cada animal foram selecionados 10 campos da região cortical renal e medidos em cada campo, 5 túbulos renais, coletando as respectivas áreas tubulares e da luz tubular renal.

As lâminas contendo os cortes histológicos foram cegadas para que os examinadores não saibam o grupo analisado e, desta forma, emitam falsos resultados.
Análise estatística

Para a análise estatística será utilizado o programa Sigma Stat versão 2.0. Os casos em que os dados apresentarem as distribuições normais e homocedásticas serão analisados utilizando-se de testes paramétricos como a análise de variância (ANOVA) seguido pelo teste de Tukey quando necessário. Caso contrário, serão utilizados testes não paramétricos, como o de Kruskal-Wallis seguido pelo teste de Dunn quando necessário. As diferenças serão consideradas estatisticamente significantes quando $p<0,05$.

\section{RESULTADOS}

Os resultados obtidos foram praticamente os mesmos com relação a área tubular e área da luz renal (Figura 1). Somente observou-se diferença significativa $(p \leq 0,05)$ no período de $192 \mathrm{~h}$ (8 dias) entre os tratamentos GS vs $G B C$, onde houve aumento da área tubular e aumento da luz renal. Análises individuais não apresentaram diferenças significativas $(p>0,05)$.
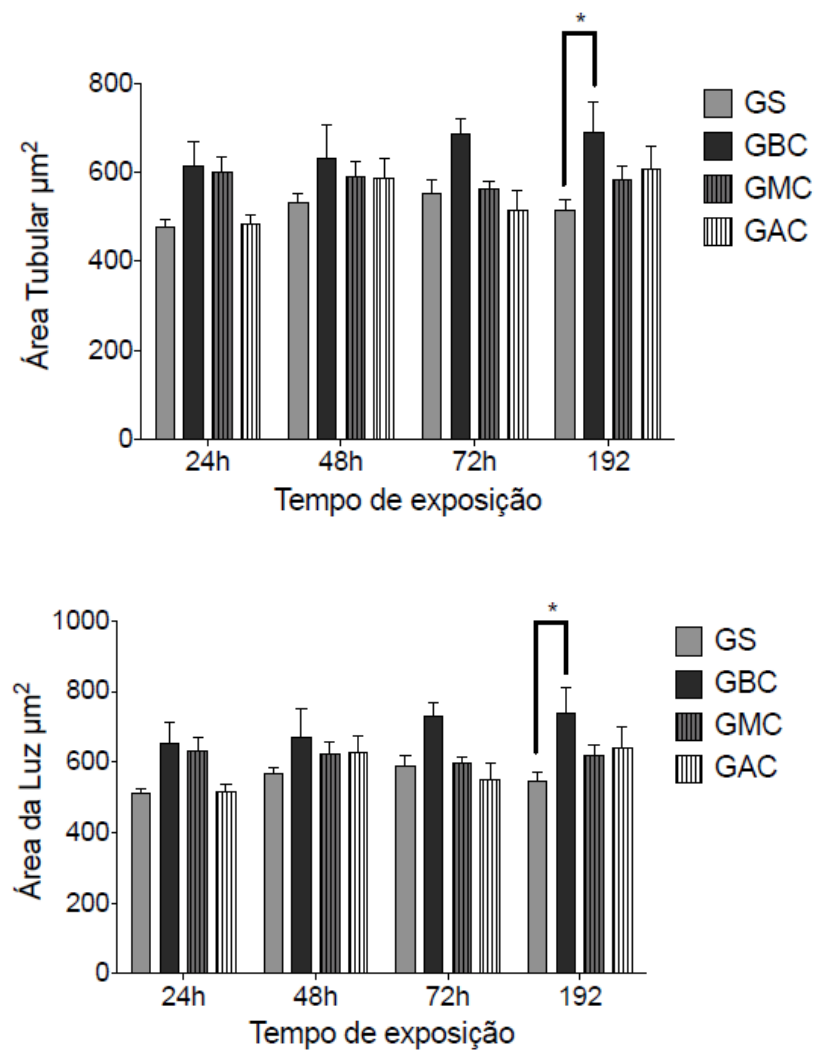

Figura 1. Comparação entre 0 tempo de exposição e dose do herbicida 2,4-D em rins de camundongos.

\section{DISCUSSÃO}

Existem diversas pesquisas disponíveis acerca dos efeitos do 2,4D, que apresentam 
qualidade e consistência, entretanto, não possuem poder estatístico suficiente para se chegar a uma conclusão a respeito da presença ou ausência de uma associação de causa e efeito entre a exposição ao 2, 4-D e o câncer, bem como mutação e alteração de sistemas nos seres humanos.

No entanto, diversas pesquisas corroboram com os resultados da presente investigação. $O$ potencial genotóxico e mutagênico do 2,4-D foi examinado em estudos que afimam que o 2,4-D não é genotóxico in vitro ou in vivo ${ }^{21-26}$.

No geral, tendo em consideração as associações epidemiológicas inconsistentes, o reconhecimento que existem muitos outros fatores que podem contribuir para a etiologia dos casos de câncer relatados, informações do banco de dados de relatórios de incidentes do PMRA, e o fato de que o peso da evidência de estudos em animais concebidos para demonstrar a causalidade não suportaram um efeito carcinogénico, a Agência de Saúde Canadense de Controle de Pestes concluiu que o 2,4-D não pode ser classificado como carcinogênico humano ${ }^{27}$.

A revisão do PMRA da base de dados toxicológica disponível para o 2,4-D determinou que, com base em estudos in vitro e in vivo, todas as formas de 2,4-D (ácido, sal ou éster) não são mutagênicas ou genotóxicas e, o peso total das evidências indica que o 2,4-D não é carcinogênico em ratos, camundongos e cães ${ }^{28}$.

Com base em avaliações dos órgãos reguladores de múltiplos países, as revisões regulatórias recentes incluem as realizadas pela Agência de Proteção Ambiental dos Estados Unidos (EPA), Health Canada, Agência Reguladora de Gerenciamento de Pestes (PMRA) e União Europeia (UE) ${ }^{29}$, o 2,4-D não apresenta potencial mutagênico em condições reais de uso. EPA ${ }^{30}$, diz que "estudos em ratos e camundongos não mostraram respostas estatisticamente significativas de tumores em nenhuma das espécies; além disso, o 2,4-D não é mutagênico."

Dentre as questões envolvidas, as evidências são interpretadas de maneiras diferentes pelos pesquisadores e revisores. Revisões publicadas recentemente e decisões dos órgãos reguladores governamentais apoiam a posição de que os dados epidemiológicos são insuficientes para estabelecer uma associação de causa e efeito entre o 2,4-D e o câncer. Muitos revisores apontam para a qualidade insuficiente com relação à exposição e a falta de consistência entre múltiplos estudos. Além disso, o número de casos de exposição frequentemente impede a existência de poder estatístico suficiente para uma avaliação robusta de uma resposta de dosagem ${ }^{21,23,31,32}$.

Dentre os estudos já concluídos, a Agência Internacional de Pesquisas sobre o Câncer (IARC) ${ }^{33}$ afirmou, em 1977, que "nenhuma avaliação da carcinogecidade deste composto (2,4-D) pôde ser feita" com relação a animais. A respeito de dados sobre seres humanos, a avaliação declara: os resultados do único estudo de corte de um pequeno número de trabalhadores expostos a diversos herbicidas, incluindo o 2,4-D, o 2,4,5-T e o 3-amina-1,2,4triazole (amitrole) não são suficientes para avaliar a carcinogenicidade do 2,4-D para o homem", concordando portanto com o presente estudo.

Em 2 de outubro de 2001, o Diretório Geral de Saúde e Proteção ao Consumidor da Comissão Europeia revalidou o registro do 2,4-D para todos os usos na União Europeia. Ao anunciar a determinação, o organismo concluiu: "[...]nenhuma associação clara entre o desenvolvimento de câncer e exposição a herbicidas fenóxidos (inclusive o 2,4-D) pôde ser estabelecida a partir dos estudos epidemiológicos disponíveis". A Comissão classificou o 2,4-D como "Sem Evidências de Carcinogenicidade".

Em 2003, a Autoridade de Gerenciamento de Riscos Ambientais da Nova Zelândia ${ }^{32}$ concluiu um processo de consultas para propostas de classificação e controle de diversas substâncias. A Autoridade determinou que "as evidências de uma relação causal entre exposição a herbicidas clorofenóxidos e o desenvolvimento do Linfoma Não Hodgkin (LNH) e outros tipos de câncer em seres humanos são insuficientes no momento e os dados disponíveis não podem ser interpretados como demonstrando a presença ou ausência de um efeito carcinogênico".

A partir de 1988, a EPA realizou uma revisão para um novo registro do 2,4-D que foi completado pela Agência em junho de 2005 com a publicação do trabalho Reregistration Evaluation Decision on $2,4-D^{34}$. A conclusão foi que "nenhum dos mais recentes estudos epidemiológicos ligou definitivamente as causas do câncer ao 2,4-D". A decisão conferiu ao 2,4-D a categoria D - Não Classificável com Relação à Carcinogenicidade Humana. Em 8 de agosto de 2007, a EPA anunciou sua decisão de não iniciar uma revisão especial do 2,4-D: "com base em 
extensas revisões científicas de muitos estudos epidemiológicos e em animais, a Agência determina que 0 peso das evidências não sustenta uma conclusão de que o 2,4-D, 2,4-DB e o 2,4-DP são provavelmente carcinógenos para seres humanos" ${ }^{\prime 35}$.

Em 2015, foram anunciadas as conclusões da Autoridade de Segurança Alimentar Europeia (EFSA), seguintes à revisão por pares de uma avaliação inicial de riscos realizada pela autoridade competente do Relator Estado Membro Grécia para a substância ativa pesticida 2,4- $D^{23}$. Elas afirmam que "se concorda desta forma que o 2,4-D, na maneira como é fabricado atualmente, apresenta improbabilidade de ter um potencial genotóxico ou represente um risco cancernogênico para seres humanos". O relatório prossegue para concluir: "Nenhuma associação conclusiva pode ser estabelecida entre a exposição a herbicidas fenóxidos (incluindo 0 ácido 2,4-D) e carcinogenicidade em seres humanos. Nenhuma evidência conclusiva existe na literatura aberta de que o 2,4-D pode exibir propriedades toxicológicas que não aquelas já concluídas com base em estudos de toxicidade realizados com a substância ativa técnica".

Nossa interpretação da literatura epidemiológica é que não há evidência convincente para qualquer efeito adverso crônico do 2,4-D em humanos. No entanto, os dados epidemiológicos são apenas uma pequena parte da informação disponível. Há uma abundância de informações da literatura de biomonitoramento. Esses dados nos informam que as pessoas com contato direto com o 2,4-D têm a maior exposição e que a maioria das populações não agrícolas tem pouca ou nenhuma exposição mensurável. Orientados pelo biomonitoramento, podemos controlar melhor a exposição e as populações-alvo mais expostas para futuras pesquisas em saúde ${ }^{29}$.

O início de saturação da depuração renal de 2,4-D em doses que são amplamente díspares de seres humanos sugerem que os resultados de toxicidade animal observados em níveis de dose ou acima da dose superestimam riscos humanos potenciais ${ }^{28,36-40}$.

Como apresentado neste documento, há evidências que demonstram falta de carcinogenicidade em animais experimentais. Existem estudos adequados envolvendo pelo menos duas espécies animais mostrando que, dentro dos limites dos testes utilizados, o 2,4-D não é carcinogênico. Além disso, há evidência inadequada de carcinogenicidade em humanos. Os estudos disponíveis são de insuficiente qualidade, coerência ou poder estatístico para permitir uma conclusão sobre a presença ou ausência de uma associação causal entre exposição e câncer. Além disso, a seção mecanicista sustenta que não há dados que evidenciam os modos de ação cancerígenos do tipo 2,4-D.

Numerosos estudos de biomonitoramento de alta qualidade existem para o 2,4-D, uma vez que este não é metabolizado e é rapidamente excretado na urina. Análises de concentrações na urina de 2,4D fornecem evidências diretas de agregado de 2,4-D após exposições de todas as fontes (ocupacionais, dieta, água, ar etc). Estudos da população geral e observadores rurais demonstraram que a exposição ao 2,4-D varia de baixa para não detectável ${ }^{41}$. É importante ressaltar que as doses de 2,4-D estimadas a partir do biomonitoramento da urina estão bem abaixo do valor de referência ${ }^{28,42,43}$.

Em conclusão os resultados obtidos a partir da área tubular e área da luz renal em camundongos nesse presente trabalho, juntamente com trabalhos já publicados, demonstraram que existe pouca evidência científica que demonstre potencial inflamatório e/ou mutagênico da exposição aguda ao ácido 2,4-diclorofenoxiacético, porém, alterações podem existir levando-se em conta o fator tempo, ou seja, numa exposição crônica ao herbicida. Apesar do tema ser estudado mundialmente por países que fazem seu uso, é necessário o desenvolvimento de mais testes para futuros esclarecimentos e tomadas de decisões.

\section{CONFLITO DE INTERESSE}

Os autores declaram não haver qualquer potencial conflito de interesse que possa interferir na imparcialidade deste trabalho científico.

\section{REFERÊNCIAS}

1. Ministério da Agricultura, Pecuária e Abastecimento. Registro de Agrotóxicos e Afins: Informações Técnicas. Brasília; 2020. Acesso em: 28 maio 2019. Disponível em: http://www.agricultura.gov.br/assuntos/insumos -agropecuarios/insumos-agricolas/agrotoxicos 
2. Departamento de Vigilância em Saúde Ambiental e Saúde do Trabalhador. Nota informativa contendo esclarecimentos sobre pulverização aérea e o controle de endemias. Fiocruz. Rio de Janeiro. 2004.

3. Dossiê ABRASCO: um alerta sobre os impactos dos agrotóxicos na saúde. Rio de Janeiro: EPSJV; São Paulo: Expressão Popular; 2015.

4. Ferreira ML. A pulverização aérea de agrotóxicos no Brasil: cenário atual e desafios. Rev Dir Sanit. 2015;15(3):18-45. DOI: http://dx.doi.org/10.11606/issn.23169044.v15i3p18-45

5. Araújo IMM; Oliveira AGRC. Agronegócio e Agrotóxicos: impactos à saúde dos trabalhadores agrícolas no nordeste brasileiro. Traba Educ Saúde. 2017;15(1):117-29. DOI: https://doi.org/10.1590/1981-7746-sol00043

6. Moreira JC, Peres F, Simões AC, Pignati WA, Dores EC, Vieira SN, et al. Contaminação de águas superficiais e de chuva por agrotóxicos em uma região do estado do Mato Grosso. Ciên Saude Colet. 2012;17(6):1557-68. DOI: https://doi.org/10.1590/S1413-

81232012000600019

7. Dores EFGC, Amorim RSS, Ribeiro ML, Lourencetti C. Currently Used Pesticides in Water Matrices in Central-Western Brazil. J Braz Chem Soc. 2013;23(8):1476-87. DOI: https://doi.org/10.1590/S0103$\underline{50532012005000008}$

8. Monteiro RT, Dellamatrice PM, Monteiro RTR. Principais aspectos da poluição de rios brasileiros por pesticidas. Rev Bras Eng Agrícola Ambient. 2014;18(12):1296-301. DOI: https://doi.org/10.1590/18071929/agriambi.v18n12p1296-1301

9. Brasil. Ministério da Saúde. Modelo De Atenção Integral À Saúde De Populações Expostas a Agrotóxicos. Departamento de Vigilância em Saúde Ambiental e Saúde do Trabalhador. Brasília. 2011.

10. Rebelo R, Vasconcelos R, Buys B. Produtos agrotóxicos e afins comercializados em 2009 no Brasil: uma abordagem ambiental. Instituto
Brasileiro do Meio Ambiente e dos Recursos Naturais Renováveis - Brasília: IBAMA, 2010

\section{2,4-D. Nortox. Bula de agrotóxico.}

12. Brasil. Instituto Brasileiro Do Meio Ambiente E Dos Recursos Naturais Renováveis. Portaria Normativa no 84, de 15 de outubro de 1996.

13. Ministério da Saúde. Sistema de Informação de Agravos de Notificação - Notificações Registradas no SINAN de intoxicação exógena no Brasil no ano de 2015.

14. Fundação Oswaldo Cruz. Evolução dos casos registrados de intoxicação humana por agente tóxico. Sistema Nacional de Informações TóxicoFarmacológicas; Rio de Janeiro; 2015. Acesso em: 28 maio 2019. Disponível em: https://sinitox.icict.fiocruz.br/dados-nacionais

15. Fundação Oswaldo Cruz. Evolução dos casos registrados de intoxicação humana por agente tóxico. Sistema Nacional de Informações TóxicoFarmacológicas; Rio de Janeiro; 2017. Acesso em: 28 maio 2019. Disponível em: https://sinitox.icict.fiocruz.br/dados-nacionais

16. Moreira JC, Jacob SC, Peres F, Lima JS, Meyer A, Oliveira-silva JJ, et al. Avaliação integrada do impacto do uso de agrotóxicos sobre a saúde humana em uma comunidade agrícola de Nova Friburgo-RJ. Ciên Saúde Colet. 2002;7(2):299-311. DOI: $\quad$ https://doi.org/10.1590/S1413$\underline{81232002000200010}$

17. Hall JE, Guyton AC. Guyton \& Hall tratado de fisiologia médica. 13.ed. Rio de Janeiro: Elsevier; 2017.

18. Staszak R. Os riscos dos agrotóxicos para a saúde humana no Reassentamento "Passo da Conquista" no município de Erechim (RS). Cad Agroecol. 2013;8(2):2011-4.

19. Faria NMX, Fassa ACGI, Facchini LA. Intoxicação por agrotóxicos no Brasil: os sistemas oficiais de informação e desafios para realização de estudos epidemiológicos. Ciên Saúde Colet. 2007;12(1):25-38.

DOI: https://dx.doi.org/10.1590/S1413$\underline{81232007000100008 .}$. 
20. Freitas SR, Longo KM, Hacon SS. Queima de biomassa e doenças respiratórias no sul da Amazônia brasileira. Rev Bras Epidemiol. 2010;13(2):337-51.

DOI: https://doi.org/10.1590/S1415-

790X2010000200015

21. Burns, CJ, Swaen GM (2012). Review of 2,4dichlorophenoxyacetic acid (2,4-D) biomonitoring and epidemiology. Crit Rev Toxicol. 2012;42:76886.

DOI: https://doi.org/10.3109/10408444.2012.710576

22. Rowland J. 2,4-Dichlorophenoxyacetic acid: review of a chronic toxicity/carcinogenicity study in rats, a carcinogenicity study in mice, and a rereview of a developmental toxicity study in rats. United States Environmental Protection Agency. Washington. 1996.

23. Conclusion on the peer review of the pesticide risk assessment of the active substance 2,4-D. EFSA J. 2015;12(9):3812.

24. Gollapudi BB, Charles JM, Linscombe VA, Day SJ, Bus JS. Evaluation of the genotoxicity of 2,4dichlorophenoxyacetic acid and its derivatives in mammalian cell cultures. Mutat Res. 1999;444:217-25. DOI: https://doi.org/10.1016/S1383-5718(99)00075-3

25. Pesticides Board, Report Of The Pesticides Board Expert Panel on 2,4-D. Wellington, New Zeland; 2000.

26. Health Canada Pest Management Regulatory Agency. Re-evaluation of the Agricultural, Forestry, Aquatic and Industrial Site Uses of $(2,4-$ Dichlorophenoxy) acetic Acid [2,4-D]. Ottawa; 2007.

27. Health Canada Pest Management Regulatory Agency. Special Review of 2,4-D: Proposed Decision for Consultation. Ottawa; 2016.

28. Pest Management Regulatory. Re-evaluation of the lawn and turf uses of (2,4Dichlorophenoxy)-acetic Acid [2,4-D]. Alternative Strategies and Regulatory Affairs Division. Ottawa; 2005.

29. Munro IC, Carlo GL, Orr JC, Sund KG, Wilson RM, Kennepohl E, Lynch BS, Jablinske M, Lee NL. A comprehensive, integrated review and evaluation of the scientific evidence relating to the safety of the herbicide 2,4-D. J Am Coll Toxicol. 1992;11:559-664. DOI: https://doi.org/10.3109/10915819209141893

30. MSL Group Andreoli. Iniciativa 2,4-D por uma Agricultura Efetiva. Acesso em: 28 maio 2019. Disponível em: https://www.iniciativa24d.com.br/revisao/ptbr/o-que-e-o-24-d/

31. Von Stackelberg K. A systematic review of carcinogenic outcomes and potential mechanisms from exposure to 2,4-D and MCPA in the environment. J Toxicol. 2013;2013:1-53. DOI: https://doi.org/10.1155/2013/371610

32. New Zealand Environmental Risk Management Authority. Substances to be transferred to the HSNO Act under section 160(1)(a): Phenoxy Herbicides. New Zealand; 2003

33. International Agency For Research On Cancer. Monographs on the evaluation of the carcinogenic risk of chemicals to man - Volume 15. World Health Organization; 1977.

34. United States Environmental Protection Agency. Reregistration Eligibility Decision for 2,4D. United States of America; 2005.

35. Environmental Protection Agency. 2,4-D, 2,4$D P$, and 2,4-DB. Decision not to initiate special review. United States of America; 2007. Acesso em: 28 maio 2019. Disponível em: http://www.gpo.gov/fdsys/pkg/FR-2007-0808/html/E7-15109.htm

36. Foran JA. Principles for the selection of doses in chronic rodent bioassays. ILSI Risk science working group on dose selection. Environ Health Perspect. 1997;105(1):18-20. DOI: https://doi.org/10.2307/3433048

37. Slikker W, Andersen ME, Bogdanffy MS, Bus JS, Cohen SD, Conolly RB, et al. Dose-dependent transitions in mechanisms of toxicity: case studies. Toxicol Appl Pharmacol. 2004;201(3):226-94. DOI: https://doi.org/10.1016/i.taap.2004.06.027

38. Timchalk C. Comparative inter-species pharmacokinetics of phenoxyacetic acid 
herbicides and related organic acids. evidence that the dog is not a relevant species for evaluation of human health risk. Toxicology. 2004;200(1):1-19.

DOI: https://doi.org/10.1016/S0300-483X(04)00178-7

39. Carmichael NG, Barton HA, Boobis AR, Cooper RL, Dellarco VL, Doerrer NG et al. Agricultural chemical safety assessment: a multisector approach to the modernization of human safety requirements. Crit Rev Toxicol. 2006;36:1-7. DOI: https://doi.org/10.1080/10408440500534354

40. Doe JE, Boobis AR, Blacker A, Dellarco V, Doerrer NG, Franklin C, et al. A tiered approach to systemic toxicity testing for agricultural chemical safety assessment. Crit Rev Toxicol. 2006;36(1),37-68. DOI: https://doi.org/10.1080/10408440500534370

41. CDC. Third National Report on Human Exposure to Environmental Chemicals. NCEH Pub. 05-0570. Atlanta, GA: Centers for Disease Control and Prevention; 2005.

42. Aylward LL, Morgan MK, Arbuckle TE, Barr DB, Burns $\mathrm{CJ}$, Alexander $\mathrm{BH}$, et al. Biomonitoring data for 2,4-dichlorophenoxyacetic acid in the United States and Canada: interpretation in a public health risk assessment context using Biomonitoring Equivalents. Environ Health Perspect. 2010;118:177-81. DOI: https://doi.org/10.1289/ehp.0900970

43. Hays SM, Aylward LL, Driver J, Ross J, Kirman C. 2,4-D exposure and risk assessment: comparison of external dose and biomonitoring based approaches. Regul Toxicol Pharmacol. 2012;64:481-9.

DOI: https://doi.org/10.1016/i.yrtph.2012.09.001. 